\title{
DISSOLUTION BEHAVIOR OF CARBAMAZEPINE SUSPENSIONS USING THE USP DISSOLUTION APPARATUS 2 AND THE FLOW-THROUGH CELL METHOD WITH SIMULATED GI FLUIDS
}

\author{
JOSE RAUL MEDINA*, ERIK AGUILAR, MARCELA HURTADO \\ Departamento Sistemas Biologicos, Universidad Autonoma Metropolitana-Xochimilco, Mexico City, Mexico \\ Email: rmlopez@correo.xoc.uam.mx
}

Received: 08 Jun 2017 Revised and Accepted: 21 Sep 2017

\section{ABSTRACT}

Objective: To characterize the dissolution behaviour of carbamazepine generic suspensions using the USP Dissolution Apparatus 2 and the flowthrough cell method with simulated gastrointestinal fluids as dissolution media.

\begin{abstract}
Methods: Tegretol ${ }^{\circledR}$ suspension and two generic formulations were tested. Dissolution studies were performed using the USP Apparatus 2 (75 rpm and $900 \mathrm{ml}$ of dissolution medium) and the flow-through cell method (laminar flow at $16 \mathrm{ml} / \mathrm{min}$ ). Simulated gastric fluid (SGF) (with and without pepsin) and simulated intestinal fluid (SIF) (without pancreatin) at $37.0 \pm 0.5{ }^{\circ} \mathrm{C}$, was used as dissolution media. The quantity of dissolved carbamazepine was determined at 5 min intervals until reaching $60 \mathrm{~min}$, at $285 \mathrm{~nm}$. Percentage dissolved at 60 min, mean dissolution time, dissolution efficiency values (model-independent parameters), as well as $t_{50 \%}$ and $t_{63.2 \%}$ were calculated (model-dependent parameters). Values for all parameters were compared between the reference and generic formulations using one-way analysis of variance (ANOVA) following a Dunnett's multiple comparison test. Dissolution data were also fitted to different fit models.
\end{abstract}

Results: Since the first sampling time, the reference product had reached $100 \%$ of drug dissolved, which was determined using USP Apparatus 2. Nevertheless, significant differences in the three model-independent parameters of generic products were found ( $\left.{ }^{*} \mathrm{P}<0.05\right)$. Dissolution data obtained with the paddle apparatus were fitted to different kinetic equations; however, usingthe flow-through cell method and SIF without pancreatin, the three drug products were fitted to the same kinetic model (Gompertz). With ANOVA-based comparisons and the flow-through cell method, significant differences were found in dissolution data of generic product A versus reference at all sampling times $\left({ }^{*} \mathrm{P}<0.05\right)$. The flowthrough cell method and SGF with pepsin were the best options to discriminate among dissolution profiles.

Conclusion: The flow-through cell method seems to be an adequate dissolution apparatus to characterize in vitro dissolution performance of Class II drugs manufactured as suspensions. For carbamazepine suspensions, SGF and laminar flow at $16 \mathrm{ml} / \mathrm{min}$ were the most appropriate conditions to discriminate among generic formulations. Given the physicochemical characteristics of carbamazepine and the environment in which the drug products were tested, these differences could be of clinical relevance.

Keywords: Carbamazepine, Flow-through cell apparatus, Simulated gastrointestinal fluids, Suspensions, USP Apparatus 2

(C) 2017 TheAuthors. Publishedby Innovare AcademicSciences Pvt Ltd. Thisisanopen accessarticleundertheCC BYlicense (http://creativecommons.org/licenses/by/4.0/) DOI: http://dx.doi.org/10.22159/ijpps.2017v9i11.21201

\section{INTRODUCTION}

In vitro dissolution studies are useful to assess the lot-to-lot quality of pharmaceutical formulations, changes in their manufacturing process and prediction of in vivo performance of some drugs. These studies are currently performed with the United States Pharmacopeia (USP) basket (USP Apparatus 1) or paddle apparatus (USP Apparatus 2). An official dissolution test for carbamazepine suspensions, using the USP Apparatus 2 at $50 \mathrm{rpm}$ with $900 \mathrm{ml}$ of water (deaerated) as the dissolution medium, has been reported elsewhere [1].

Generic drug products are off-patent formulations that contain the same active ingredient at the same dose as the reference products. The best way to ensure an adequate in vivo performance of a generic formulation is to conduct a bioequivalence study in humans. However, in vitro dissolution studies can contribute to establishing the interchangeability of generic formulations [2]. Recently, some authors have been concerned about the safe interchangeability between reference products and their generic counterparts or even among generic formulations $[3,4]$.

Carbamazepine is a drug to treat epilepsy, a persistent long-lasting medical neurological state or situation characterized by repeated, frequent and occasional seizures as a part of abnormal signal variation from neurons, which affects $1 \%$ of the worldwide population [5]. This compound has a low solubility and high permeability [6] and according to the Bio-pharmaceutics Classification System, drugs with these characteristics are of Class II. A feature of these drugs is that their absorption is dissolution rate limited. Compounds belonging to Class II are eligible to establish a significant in vitro/in vivo correlation
(IVIVC), hence the appropriate selection of dissolution test conditions is important to have a method able to discriminate among drug products with potential problems of bioavailability.

Simulating gastrointestinal conditions is essential to adequately predict in vivo behaviour of poorly soluble drugs [7]. For immediaterelease dosage forms containing a Class II drug, solubilization and formulation properties have a substantial effect on in vitro and in vivo dissolution. In vitro dissolution profiles should be evaluated during drug development by means of bio-relevant tests (using bio-relevant media combined with bio-relevant hydrodynamics appropriate for the formulation), so that a significant IVIVC can be established [8]. Drug absorption may be affected by several physiological factors, including the volume and composition of gastrointestinal fluids, the $\mathrm{pH}$ and buffer capacity of these fluids, digestive enzymes, contraction patterns, and bacterial flora in the gut [9]. Simulated human fluids have been widely used to mimic the natural environment in which the dosage forms will be administered and to evaluate the predictive capability of a dissolution test. Simulated gastric fluid (SGF) with or without pepsin and simulated intestinal fluid (SIF) with or without pancreatin are commonly used as dissolution media.

The flow-through cell method (USP Apparatus 4) is an alternative dissolution equipment $[10,11]$. Its advantages over USP Apparatuses 1 and 2 have been widely demonstrated, especially for the study of in vitro dissolution behaviour of poorly water-soluble drugs $[12,13]$. The flow-through cell apparatus permits continuous extraction of the drug, simulating absorption into the systemic circulation and generating an intermittent flow of the dissolution medium into the cell where the dosage form is placed [14]. It can be used as an open system, allowing 
release under sink conditions, which facilitates the dissolution of poorly soluble drugs,and changing the dissolution medium within a $\mathrm{pH}$ range of physiological relevance [15].

Despite the advantages of the flow-through cell apparatus over USP Apparatuses 1 and 2, little information is available on the in vitro release of carbamazepine using the USP Apparatus 4 and simulated gastrointestinal fluids.

The aim of this study was to characterize the dissolution behaviour of carbamazepine from reference and two generic formulations, using the flow-through cell apparatus and SGF with and without pepsin and SIF without pancreatin. The dissolution profiles of the reference and two generic formulations thus obtained were compared with the dissolution profiles obtained with the USP Apparatus 2 using model-independent, model-dependent and analysis of variance (ANOVA)-based comparisons.

\section{MATERIALS AND METHODS}

\section{Reagents and drug products}

Carbamazepine and pepsin were purchased from Sigma-Aldrich Co. (St. Louis MO, USA). Ethanol, sodium chloride, sodium hydroxide and potassium phosphate monobasic were purchased from J. T. BakerMexico. Tegretol ${ }^{\circledR}$ suspension (Novartis Farmaceutica SA de CV, Mexico) containing carbamazepine $(2 \mathrm{~g} / 100 \mathrm{ml})$ was used as areference (coded as R), since this brand has been established as the reference drug product by Mexican health authorities (COFEPRIS) [16]. Two generic formulations (coded as A and B) containing the same dose were also used.

\section{Dissolution studies}

Dissolution profiles of carbamazepine suspension were obtained using two automated devices for dissolution testing, a USP Apparatus 2 (Sotax AT-7 Smart, Switzerland) at $75 \mathrm{rpm}$ and $900 \mathrm{ml}$ of dissolution media at $37.0 \pm 0.5{ }^{\circ} \mathrm{C}$ and a USP Apparatus 4 (Sotax CE6, Switzerland) with 22.6-mm cells (i.d.) and laminar flow at 16 $\mathrm{ml} / \mathrm{min}$. SGF with and without pepsin as well as SIF at pH 6.8 without pancreatin were prepared according to the USP procedure [1]. After $15 \mathrm{~min}$ of mechanical agitation and with the aid of a syringe, a sample of $1 \mathrm{ml}$ of suspension was added to each vessel or cell. Sequential sampling, using nitrocellulose filters, was performed every $5 \mathrm{~min}$ until reaching $60 \mathrm{~min}$, with 12 replicates. The amount of dissolved carbamazepine was determined with a standard calibration curve at $285 \mathrm{~nm}$. Standard solutions of carbamazepine 1 $\mathrm{mg} / \mathrm{ml}$ ) were prepared by serial dilutions of stock solutions in SGF with and without pepsin, and in SIF without pancreatin to achieve concentrations of $2.5-20 \mu \mathrm{g} / \mathrm{ml}$.

\section{Data analysis}

The dissolution profiles of generic formulations vs. reference product were compared by model-independent, model-dependent and analysis of variance (ANOVA)-based methods [17]. For modelindependent methods, the mean dissolution time (MDT) and dissolution efficiency (DE) were calculated. Furthermore, the percentage of drug dissolved at $60 \mathrm{~min}$ was also taken for comparative purposes. For calculation of DE and MDT values, the Excel add-in DDSolver was used [18]. For model-dependent comparisons, dissolution data were fitted to Weibull, logistic, Gompertz and probit models. The model with the highest adjusted determination coefficient $\left(\mathrm{R}^{2}\right.$ adjusted $)$ and the minimum Akaike information criterion (AIC) was taken as the best fit model [17]. Data analysis was performed using the Excel add-in DDSolver. Additionally, dissolution data were fitted to sigmoidal model (Eq. 1) using SigmaPlot software (version 11.0).

$$
\mathrm{y}=\frac{\mathrm{a}}{1+\mathrm{e}^{-\left(\frac{x-x_{0}}{\mathrm{~b}}\right)}} \text { Eq. [1] }
$$

Where $x$ is the time of the test, $y$ is the percentage of drug dissolved at time t, and $a, b$, and $x_{0}$ are constants. With these parameters, the $t_{50 \%}$ and $t_{63.2 \%}$ values were calculated. The ANOVA-based comparisons were carried out with the percentage of carbamazepine dissolved at each time point. In the three methods used to evaluate the dissolution profiles, the values were compared by one-way ANOVA following a Dunnett's multiple comparison test. Differences were considered significant if $* \mathrm{P}<0.05$.

\section{RESULTS AND DISCUSSION}

\section{Dissolution profiles}

The dissolution profiles of carbamazepine suspensions, determined using the USP Apparatus 2 and the flow-through cell method with simulated gastrointestinal fluids, are shown in fig. 1.

It is interesting to note different dissolution performances of all drug products studied with the USP Apparatus 2 and the flowthrough cell method. Even under a hydrodynamic environment of the USP Apparatus 2, the dissolution profile of the reference product is totally different from those of generic formulations. From the first $5 \mathrm{~min}$. of the test, the complete dose of carbamazepine was dissolved regardless of the dissolution medium used. Generic formulations A and B show a typical dissolution pattern with the low influence of dissolution medium, except for dissolution profile of generic formulation B with SGF containing pepsin, where from the minute 20 till the end of the test $60-70 \%$ of the drug was dissolved.

Under the hydrodynamic environment of the flow-through cell method, all drug products showed a slow dissolution pattern. Some researchers have suggested that this result can be explained by hydrodynamic conditions that characterize the USP Apparatus 4, which lacks an agitation mechanism; also, by the fact that dosage form and drug particles are continuously exposed to uniform laminar flow, similar to the natural gastrointestinal tract environment, which causes a different dissolution pattern [19]. When using the flow-through cell method, cell size, glass bead type, and flow rate are critical factors in determining this pattern. The use of the flow rate of $16 \mathrm{ml} / \mathrm{min}$ is suggested by the European and US Pharmacopeia [20]. Due to coefficients of variation out of established criteria, no $f_{2}$ similarity factor values were calculated. This criterion (comparisons by $f_{2}$ value) would not be applicable to the data generated in the USP Apparatus 2 due to complete dissolution of the reference product $(100 \%)$ from the first sampling time. In the flowthrough cell with SIF without pepsin as dissolution medium, reference product dissolved less than $25 \%$ of the dose which does not allow an adequate comparison of dissolution profiles.

\section{Model-independent comparisons}

The mean values standard error of the mean (SEM) of percentage dissolved at $60 \mathrm{~min}$ and model-independent parameters MDT and DE are shown in table 1.

In all comparisons, significant differences between the generic formulations $\mathrm{A}$ and $\mathrm{B} v$ s. reference product were observed $\left({ }^{*} \mathrm{P}<0.05\right)$, except when the flow-through cell method and SIF without pancreatin were used as dissolution medium. The model-independent parameters MDT and DE are commonly used to compare dissolution profiles. MDT represents the average time at which $63.2 \%$ of the dose is dissolved, and DE relates the area under the curve of the dissolution profile to the total area of the rectangle formed by the theoretical dissolution of $100 \%$ dose and the time interval of the test. MDT and DE have been also proposed as adequate parameters for IVIVC levels B and C [21]. Level $B$ is defined as the relationship between MDT and mean residence time (average time that a molecule stays in the body), and both parameters are calculated by statistical moment analysis. Level C is defined as the association between a dissolution time point $\left(\mathrm{t}_{50 \%}, \mathrm{t}_{85 \%}\right.$, etc.) and one pharmacokinetic parameter, such as area under the curve, $\mathrm{C}_{\max }$, or $\mathrm{T}_{\max }$. $\mathrm{DE}$ is used by some researchers as an appropriate parameter to express the global drug dissolution performance, useful for comparing dissolution profiles [22], or relating them to some in vivo parameter.

\section{Model-dependent comparisons}

The $\mathrm{R}^{2}$ adjusted and the AIC mean values for carbamazepine suspensions are shown in table 2 .

According to the established criterion to choose the best fit model, the dissolution data of all drug products were adjusted to differential equations, except the data generated with the use of flow-through cell method and FIS without pancreatin as dissolution medium. Only under such conditions, the reference product and generic formulations $\mathrm{A}$ and B fitted to a single model (Gompertz), but due to the low dissolution of the reference product, it was not possible to perform the comparison 
of dissolution profiles. However, based on the shape of the profiles, especially of those obtained with the flow-through cell method, the sigmoidal equation was used to fit all data. The coefficient of determination $\left(\mathrm{R}^{2}\right)$ and the $\mathrm{t}_{\mathrm{x} \%}$ mean \pm SEM are shown in table 3 .

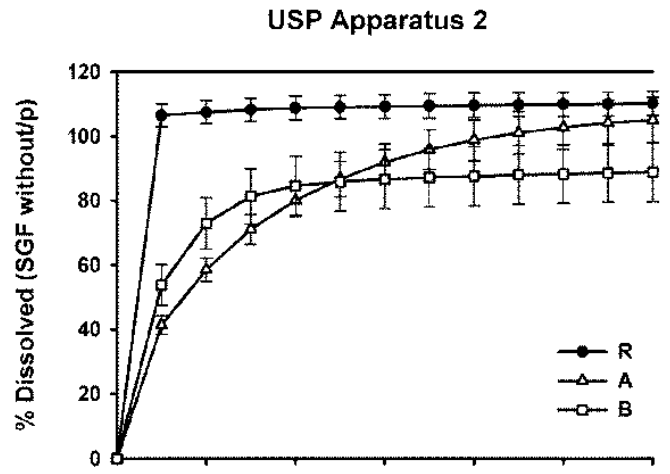

Flow-through cell method
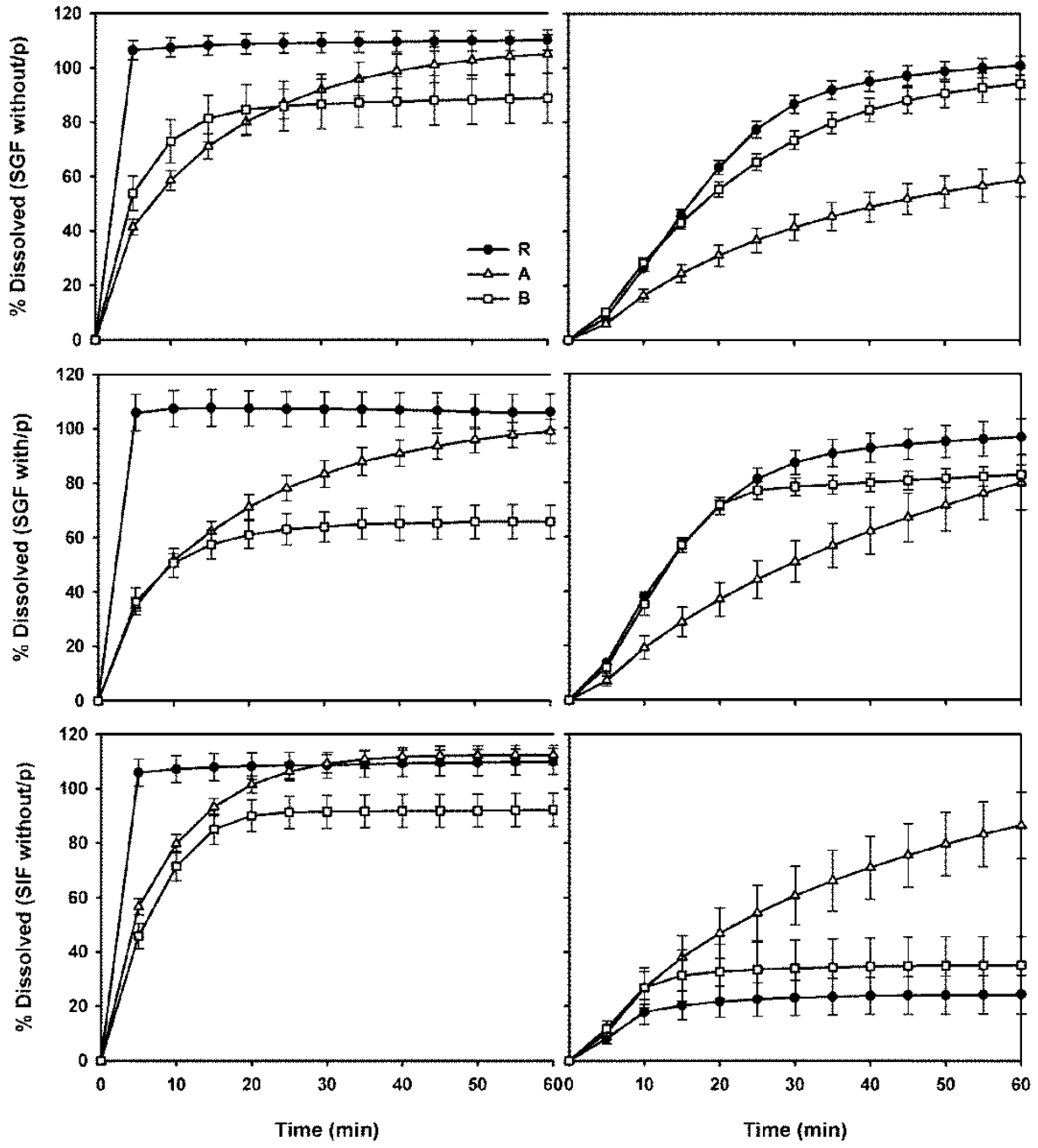

Fig. 1: Dissolution profiles of carbamazepine suspensions. R: reference, $A$ and $B$ : generic formulations. mean $\pm S D, n=12$

Table 1: Model-independent parameters of carbamazepine suspensions

\begin{tabular}{llllll}
\hline USP & Medium & Code & Diss. at 60 min (\%) & MDT (min) & DE (\%) \\
\hline 2 & I & R & $110.18 \pm 1.07$ & $3.14 \pm 0.03$ & $104.42 \pm 1.01$ \\
& A & $104.99 \pm 2.08$ & $13.08 \pm 0.13^{*}$ & $82.07 \pm 1.52^{*}$ \\
& & B & $88.87 \pm 2.65^{*}$ & $6.59 \pm 0.10^{*}$ & $79.13 \pm 2.41^{*}$ \\
& II & R & $106.22 \pm 1.91$ & $2.11 \pm 0.15$ & $102.46 \pm 1.80$ \\
& A & $99.13 \pm 1.29^{*}$ & $14.73 \pm 0.19^{*}$ & $74.81 \pm 1.15^{*}$ \\
& B & $65.86 \pm 1.77^{*}$ & $7.39 \pm 0.26^{*}$ & $57.75 \pm 1.55^{*}$ \\
& R & $109.97 \pm 1.38$ & $3.23 \pm 0.04$ & $104.05 \pm 1.34$ \\
& III & A & $112.34 \pm 1.04$ & $8.28 \pm 0.16^{*}$ & $96.83 \pm 0.89^{*}$ \\
& B & $92.20 \pm 1.77^{*}$ & $6.80 \pm 0.25^{*}$ & $81.71 \pm 1.42^{*}$ \\
& R & $100.93 \pm 1.02$ & $18.31 \pm 0.12$ & $70.13 \pm 0.75$ \\
& I & B & $58.87 \pm 1.80^{*}$ & $22.39 \pm 0.32^{*}$ & $36.91 \pm 1.20^{*}$ \\
& & B & $94.26 \pm 1.65^{*}$ & $19.69 \pm 0.32^{*}$ & $63.28 \pm 0.89^{*}$ \\
& R & $96.75 \pm 1.92$ & $15.24 \pm 0.28$ & $72.11 \pm 1.12$ \\
& A & $79.94 \pm 2.90^{*}$ & $25.01 \pm 0.28^{*}$ & $46.72 \pm 1.95^{*}$ \\
& B & $82.81 \pm 1.04^{*}$ & $13.09 \pm 0.25^{*}$ & $64.71 \pm 0.59^{*}$ \\
& R & $24.27 \pm 2.05$ & $9.06 \pm 0.67$ & $20.48 \pm 1.62$ \\
& III & A & $86.50 \pm 3.53^{*}$ & $22.26 \pm 0.51^{*}$ & $54.61 \pm 2.66^{*}$ \\
\hline
\end{tabular}

MDT: mean dissolution time, DE: dissolution efficiency, I: SGF without pepsin, II: SGF with pepsin, III: SIF without pancreatin, R: reference, A and B: generic formulations. mean $\pm \mathrm{SEM}, \mathrm{n}=12 .{ }^{*} \mathrm{P}<0.05$ 
Table 2: Criteria used for the selection of the best fit model

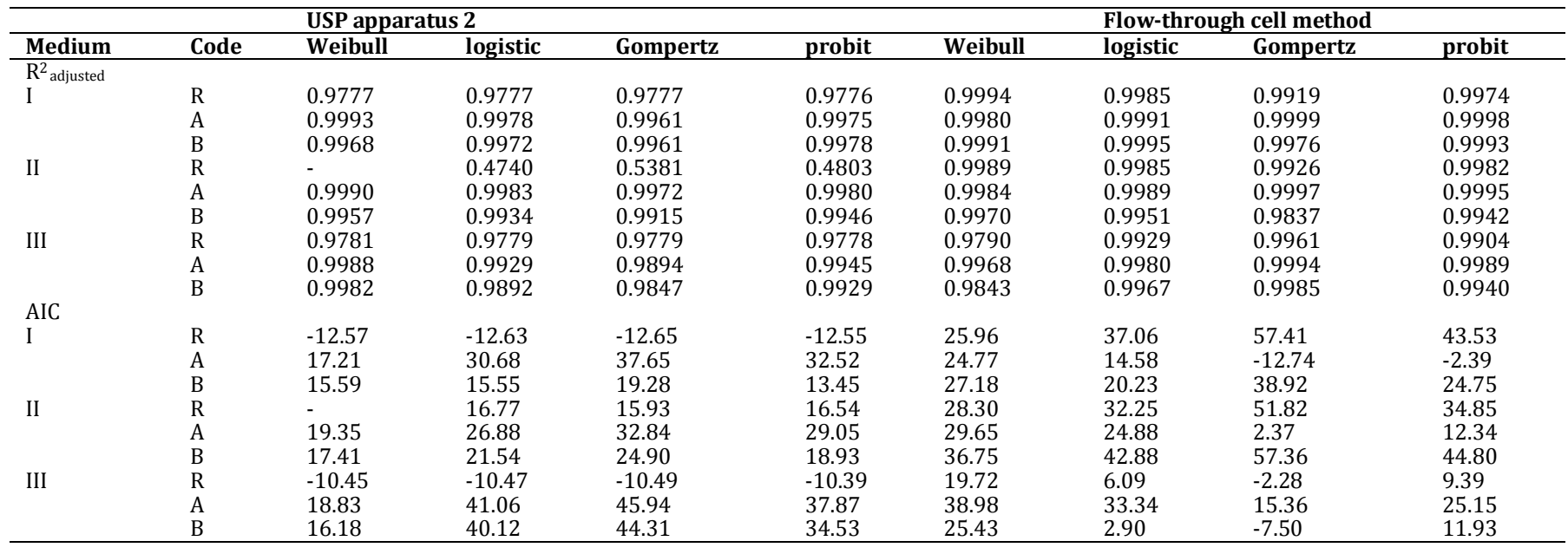

AIC: Akaike Information Criterion. Mean, $n=12$

Table 3: Parameters of sigmoidal model with $t_{50 \%}$ and $t_{63.2 \%}$ values

\begin{tabular}{|c|c|c|c|c|c|c|c|c|}
\hline USP & Medium & Code & $\mathbf{R}^{2}$ & $a$ & $b$ & $X_{0}$ & $\mathbf{t}_{50 \%}$ & $t_{63.2 \%}$ \\
\hline \multirow[t]{9}{*}{2} & I & $\mathrm{R}$ & 0.9796 & 110.21 & 18.02 & -56.22 & $\dagger$ & $\dagger$ \\
\hline & & A & 0.9947 & 104.15 & 10.18 & 8.13 & $7.38 \pm 0.37$ & $12.66 \pm 0.48$ \\
\hline & & $\mathrm{B}$ & 0.9938 & 87.77 & 4.79 & 2.7 & $4.19 \pm 0.39$ & $7.60 \pm 0.65$ \\
\hline & II & $\mathrm{R}$ & 0.6556 & 106.13 & -8.09 & 62.01 & $\dagger$ & $\dagger$ \\
\hline & & A & 0.9928 & 98.39 & 11.06 & 9.92 & $10.37 \pm 0.35$ & $16.53 \pm 0.56$ \\
\hline & & B & 0.9915 & 65.40 & 5.89 & 3.35 & $10.67 \pm 0.90$ & $17.09 \pm 0.73$ \\
\hline & III & $\mathrm{R}$ & 0.9712 & 110.18 & 21.79 & -65.57 & $\dagger$ & $\dagger$ \\
\hline & & A & 0.9976 & 112.02 & 6.52 & 4.61 & $3.21 \pm 0.19$ & $6.30 \pm 0.21$ \\
\hline & & B & 0.9994 & 91.93 & 3.89 & 5.05 & $5.77 \pm 0.25$ & $8.20 \pm 0.32$ \\
\hline \multirow[t]{9}{*}{4} & I & $\mathrm{R}$ & 0.9950 & 98.63 & 6.23 & 16.54 & $16.73 \pm 0.16$ & $20.18 \pm 0.22$ \\
\hline & & A & 0.9845 & 57.74 & 10.18 & 19.93 & $42.39 \pm 2.84 *$ & $\dagger$ \\
\hline & & $\mathrm{B}$ & 0.9893 & 92.35 & 8.35 & 17.42 & $18.82 \pm 0.29$ & $23.96 \pm 0.38$ \\
\hline & II & $\mathrm{R}$ & 0.9923 & 94.51 & 5.90 & 13.16 & $13.86 \pm 0.15$ & $17.35 \pm 0.21$ \\
\hline & & A & 0.9857 & 80.56 & 11.78 & 23.81 & $30.15 \pm 1.46^{*}$ & $41.04 \pm 2.58 *$ \\
\hline & & B & 0.9963 & 80.70 & 4.02 & 11.33 & $13.31 \pm 0.21$ & $16.55 \pm 0.18$ \\
\hline & III & $\mathrm{R}$ & 0.9751 & 23.69 & 3.64 & 6.92 & $\dagger$ & $\dagger$ \\
\hline & & A & 0.9811 & 85.38 & 11.02 & 19.82 & $24.37 \pm 2.00$ & $34.12 \pm 3.98$ \\
\hline & & $\mathrm{B}$ & 0.9855 & 34.30 & 2.87 & 6.69 & $t$ & $\dagger$ \\
\hline
\end{tabular}

mean \pm SEM, $n=12 .{ }^{*} \mathrm{P}<0.05$. $†$ No real values were found.

Table 4: Dunnett's multiple comparison test for the percentage of carbamazepine dissolved at each time point obtained with the flowthrough cell method

\begin{tabular}{|c|c|c|c|c|c|}
\hline \multirow[b]{2}{*}{ Comparison } & \multirow[b]{2}{*}{ Time (min) } & \multicolumn{2}{|c|}{ SGF withoutpepsin } & \multicolumn{2}{|c|}{ SGF withpepsin } \\
\hline & & Difference & $* \mathbf{P}$ & Difference & ${ }^{*} \mathbf{P}$ \\
\hline \multirow[t]{12}{*}{ A vs. R } & 5 & 2.22 & $<0.05$ & 6.75 & $<0.05$ \\
\hline & 10 & 10.12 & $<0.05$ & 18.77 & $<0.05$ \\
\hline & 15 & 21.62 & $<0.05$ & 28.06 & $<0.05$ \\
\hline & 20 & 32.34 & $<0.05$ & 34.34 & $<0.05$ \\
\hline & 25 & 40.72 & $<0.05$ & 36.95 & $<0.05$ \\
\hline & 30 & 45.34 & $<0.05$ & 36.46 & $<0.05$ \\
\hline & 35 & 46.47 & $<0.05$ & 34.00 & $<0.05$ \\
\hline & 40 & 46.11 & $<0.05$ & 30.55 & $<0.05$ \\
\hline & 45 & 45.29 & $<0.05$ & 26.93 & $<0.05$ \\
\hline & 50 & 44.27 & $<0.05$ & 23.39 & $<0.05$ \\
\hline & 55 & 43.16 & $<0.05$ & 20.01 & $<0.05$ \\
\hline & 60 & 42.06 & $<0.05$ & 16.81 & $<0.05$ \\
\hline \multirow[t]{12}{*}{ B vs. R } & 5 & -2.08 & $<0.05$ & 1.71 & $<0.05$ \\
\hline & 10 & -2.00 & $<0.05$ & 2.66 & $>0.05$ \\
\hline & 15 & 2.86 & $<0.05$ & -0.17 & $>0.05$ \\
\hline & 20 & 8.01 & $<0.05$ & -0.44 & $>0.05$ \\
\hline & 25 & 12.04 & $<0.05$ & 4.25 & $>0.05$ \\
\hline & 30 & 13.35 & $<0.05$ & 8.90 & $<0.05$ \\
\hline & 35 & 12.10 & $<0.05$ & 11.53 & $<0.05$ \\
\hline & 40 & 10.36 & $<0.05$ & 12.75 & $<0.05$ \\
\hline & 45 & 9.05 & $<0.05$ & 13.29 & $<0.05$ \\
\hline & 50 & 8.05 & $<0.05$ & 13.53 & $<0.05$ \\
\hline & 55 & 7.24 & $<0.05$ & 13.79 & $<0.05$ \\
\hline & 60 & 6.67 & $<0.05$ & 13.94 & $<0.05$ \\
\hline
\end{tabular}


As can be seen, comparisons of dissolution profiles by modelindependent methods were only possible with data generated by the flow-through cell method as well as with SGF without pepsin (using $\mathrm{t}_{50 \%}$ data) and SGF with pepsin (using $\mathrm{t}_{50 \%}$ and $\mathrm{t}_{63.2 \%}$ data) as dissolution media. Comparing these three sets of data, the dissolution profile of generic formulation $\mathrm{B}$ was considered similar to that of the reference product $\left({ }^{*} \mathrm{P}>0.05\right)$. A previous report showed that sigmoidal model was suitable for adjusting dissolution data of generic drug products, generated with the flow-through cell method, and two derived parameters of this fit $\left(t_{50 \%}\right.$ and $t_{63.2 \%}$ values) were used to compare their dissolution profiles with the dissolution profile of the reference product [23]. The $\mathrm{t}_{\mathrm{x} \%}$ and sampling time values are commonly used to characterize the drug release rate. The $t_{\mathrm{x} \%}$ value corresponds to the time necessary to release a determined percentage of drug (e. g., $\mathrm{t}_{10 \%}, \mathrm{t}_{50 \%}, \mathrm{t}_{90 \%}$ ) and the sampling time corresponds to the amount of drug dissolved in that time (e. g., $\mathrm{t}_{10}$ $\left.\min , t_{50 \mathrm{~min}}, \mathrm{t}_{90 \mathrm{~min}}\right)$. Pharmacopeias use this parameter as an acceptable limit for the dissolution test (e. g., $\mathrm{t}_{45 \mathrm{~min}} \geq 80 \%$ ) [24].

\section{ANOVA-based comparisons}

ANOVA-based comparisons were used to compare the dissolution data of carbamazepine suspensions. The advantage of this approach is that it is not restricted to any of the requirements of modelindependent or model-dependent comparisons. Comparisons among the generic formulations A and B vs. reference product were carried out at all sampling times only with data obtained by the flowthrough cell method, with SGF without pepsin and SGF with pepsin as dissolution media. Results are shown in table 4 .

Dissolution data were compared by one-way ANOVA followed by a Dunnett's multiple comparisons test. This analysis does not compare the complete dissolution profile but compares the values at each sampling time in order to find the source of differences. The application of this approach allowed us to state that dissolution data of generic formulation $B$ were similar to dissolution data of the reference product, under the same experimental conditions (flowthrough cell method and SGF with pepsin as dissolution medium) in the time interval of 10 to $25 \mathrm{~min}$. As additional data, the gastric emptying time is 15 to $20 \mathrm{~min}$ under fasting conditions [25]. This time is very important for an oral suspension that controls seizures and is expected to have rapid pharmacological action.

The three ways of comparing the dissolution data emphasized the high sensitivity and discriminative capacity of the flow-through cell method in the evaluation of dissolution behavior of carbamazepine suspensions in comparison to the official USP paddle apparatus. Sensitivity, discriminating capacity and reproducibility are important factors to be considered for a dissolution test. The flowthrough cell method establishes reasonable conditions for the evaluation of generic drugs which allow determining differences in dissolution when they really reflect aspects of drug product quality. Pharmacopeial conditions appear not to be the most appropriate for exhibiting such differences. A generic product may be defined as a product that has been produced by chemical synthesis, contains the same active ingredient as drug and is capable of exhibiting therapeutic equivalence as the reference product [26]; the USP Apparatus 4 helps to maintain these quality standards. Since its introduction, the flow-through cell method showed greater advantages in the evaluation of the rate and extent of dissolution performance compared to the official USP Apparatuses 1 and 2 [19]. The hydrodynamic environment generated by this equipment simulates in vivo performance better than other apparatuses and several reports confirm an adequate correlation with in vivo results $[19,27,28]$. Because little information is available on carbamazepine suspensions under hydrodynamic environment generated by the flowthrough cell method, additional research is necessary. It is important to emphasize that this is the first study on the dissolution behavior of carbamazepine suspensions using the flow-through cell method and simulated gastrointestinal fluids. In vivo performance of these drug products should be evaluated using appropriate clinical protocols.

\section{CONCLUSION}

The flow-through cell method seems to be an adequate dissolution apparatus to characterize in vitro dissolution performance of Class II drugs manufactured as suspensions. For carbamazepine suspensions, SGF and laminar flow at $16 \mathrm{ml} / \mathrm{min}$ were the most appropriate conditions to discriminate among generic formulations. Given the physicochemical characteristics of carbamazepine and the environment in which the drug products were tested, these differences could be of clinical relevance.

\section{AUTHORS CONTRIBUTION}

JR Medina proposed the research protocol, supervised and directed the development of the work. E. Aguilar contributed to the collection of data and its fittings as well as to thediscussion of results and $\mathrm{M}$. Hurtado assisted in the statistical analysis of data, writing and revision of the article.

\section{CONFLICT OF INTERESTS}

All authors have none to declare

\section{REFERENCES}

1. United States Pharmacopeia and National Formulary USP 40NF 35; The United States Pharmacopeial Convention, Inc: Rockville MD; 2017.

2. Shokin IE, Ramenskaya GV, Vasulenko GF, Malalshenko EA. Assessment of the possibility of using comparative in vitro dissolution kinetics (biowaiver) instead of in vitro bioequivalence evaluation for establishing the interchangeability of generic drugs. PharmChem J 2011;45:107-9.

3. Ruiz ME, Gregorini A, Takevi A, Volonté MG. Dissolution studies of generic medications: new evidence of deviations from the transitivity principle. Dissolution Technol 2012;19:13-24.

4. Al Almeri MN, Nayuni N, Anil Kumar KG, Perrett D. The differences between the branded and generic medicines using solid dosage forms: in vitro dissolution testing. Results PharmaSci 2012;2:1-8.

5. Ramesh K, Krishnapriya M, Asha P, Nair SC. Preparation and evaluation of chitosan sodium alginate carbamazepine microspheres. Asian J Pharm Clin Res 2017;10:271-6.

6. Lindenberg M, Kopp S, Dressman JB. Classification of orally administered drugs on the World Health Organization model list of essential medicines according to the biopharmaceutics classification system. Eur J Pharm Biopharm 2004;58:265-78.

7. Zoeller T, Klein S. Simplified biorelevant media for screening dissolution performance of poorly soluble drugs. Dissolution Technol 2007;14:8-13.

8. Wang Q, Fotaki N, Mao Y. Biorelevant dissolution: methodology and application in drug development. Dissolution Technol 2009;16:6-12.

9. Marques MRC, Loebenberg R, Almukainzi M. Simulated biological fluids with possible application in dissolution testing. Dissolution Technol 2011;18:15-28.

10. Singh I, Aboul-Enein HY. Advantages of USP apparatus IV (flowthrough cell apparatus) in dissolution studies. J Iran ChemSoc 2006;3:220-2.

11. Qui S, Wang K, Li M. In vitro dissolution studies of immediaterelease and extended-release formulations using flow-through cell apparatus 4. Dissolution Technol 2014;21:6-15.

12. Sunesen VH, Pedersen BL, Kristensen HG, Müllertz A. In vivoin vitro correlations for a poorly soluble drug, danazol, using the flow-through dissolution method with biorelevant dissolution media. Eur J Pharm Sci 2005;24:305-13.

13. Szymanska E, Winnicka K. Comparison of theflow-through cell and paddle methods for testing vaginal tablets containing a poorly water-soluble drug. Trop J Pharm Res 2013;12:39-44.

14. Qureshi SA, Caille G, Brien R, Piccirilli G, Yu V, McGilveray IJ. Application of the flow-through dissolution method for the evaluation of oral formulations of nifedipine. Drug DevInd Pharm 1994;20:1869-82.

15. Fotaki N, Reppas C. The flow-through cell methodology in the evaluation of intralumenal drug release characteristics. Dissolution Technol 2005;12:17-21.

16. Listado de Medicamentos de Referencia,Cofepris, Mexico. Available from: http://www.gob.mx/cms/uploads/ attachment/file/ 178695/IMR_2017-07_V001.pdf.[Last accessed on 07 Jul 2017]

17. Yuksel N, Kanik AE, Baykara T. Comparison of in vitro dissolution profiles by ANOVA-based, model-dependent and independentmethods. Int J Pharm 2000;209:57-67.

18. Zhang $\mathrm{Y}$, Huo M, Zhou J, Zou A, Li W, Yao C,et al. DD solver: an add-in program for modelling and comparison of drug dissolution profiles. AAPS J 2010;12:263-71. 
19. Langenbucher F, Benz D, Kurth W, Moller H, Otz M Standardized flow-cell method as an alternative to existing pharmacopoeial dissolution testing. Pharm Ind 1989;51:1276-81.

20. Steffansen B, Brodin B, Und Nielsen C. editors. Molecular Biopharmaceutics. ULLA Pharmacy Series. Pharmaceutical Press; 2010.

21. Demirturk E, Oner L. In vitro-in vivo correlations. FABAD J Pharm Sci 2003;28:215-24.

22. Anderson NH, Bauer M, Boussac N, Khan-Malek R, Munden P, Sardaro M. An evaluation of fit factors and dissolution efficiency for the comparison of in vitro dissolution profiles. J Pharm Biomed Anal 1998;17:811-22.

23. Medina JR, Cortes M, Romo E. Comparison of the USP apparatus 2 and 4 for testing the in vitro release performance of ibuprofen generic suspensions. Int J App Pharm 2017;9:90-5.
24. Costa P, Sousa Lobo JM. Modeling and comparison of dissolution profiles. Eur J Pharm Sci 2001;13:123-33.

25. Alt $A$, Potthast $H$, Moessinger $J$, Sickmüller $B$, Oeser $H$ Biopharmaceutical characterization of sotalol-containing oral immediate release drug products. Eur J Pharm Biopharm 2004;58:145-50.

26. Malipatil NB, haridas K, Prithvi SD. An overview of biosimilars. Asian J Pharm Clin Res 2015;8:23-7.

27. Emara LH, El-Menshawi BS, Estefan MY. In vitro-in vivo correlation and comparative bioavailability of vincamine in prolonged-release preparations. Drug DevInd Pharm 2000;26:243-51.

28. Štefanic M, Locatelli I, Vrecer F, Sever T, Mrhar A, Bogataj A. The influence of gastric emptying kinetics on the drug release from enteric coated pellets in afasted state: an in vitro/in vivo correlation. Eur J Pharm Biopharm 2012;82:376-82. 